\title{
Review Article \\ Zeaxanthin: Review of Toxicological Data and Acceptable Daily Intake
}

\author{
James A. Edwards \\ NIC-RD/HN Toxicology and Kinetics, DSM Nutritional Products Ltd., Wurmisweg 576, 4303 Kaiseraugst, Switzerland \\ Correspondence should be addressed to James A. Edwards; james-a.edwards@dsm.com
}

Received 29 October 2015; Accepted 6 December 2015

Academic Editor: Joan E. Roberts

Copyright ( 2016 James A. Edwards. This is an open access article distributed under the Creative Commons Attribution License, which permits unrestricted use, distribution, and reproduction in any medium, provided the original work is properly cited.

\begin{abstract}
Zeaxanthin is a nutritional carotenoid with a considerable amount of safety data based on regulatory studies, which form the basis of its safety evaluation. Subchronic OECD guideline studies with mice and rats receiving beadlet formulations of high purity synthetic zeaxanthin in the diet at dosages up to $1000 \mathrm{mg} / \mathrm{kg}$ body weight (bw)/day, and in dogs at over $400 \mathrm{mg} / \mathrm{kg}$ bw/day, produced no adverse effects or histopathological changes. In developmental toxicity studies, there was no evidence of fetal toxicity or teratogenicity in rats or rabbits at dosages up to 1000 or $400 \mathrm{mg} / \mathrm{kg}$ bw/day, respectively. Formulated zeaxanthin was not mutagenic or clastogenic in a series of in vitro and in vivo tests for genotoxicity. A 52-week chronic oral study in Cynomolgus monkeys at doses of 0.2 and $20 \mathrm{mg} / \mathrm{kg} \mathrm{bw} /$ day, mainly designed to assess accumulation and effects in primate eyes, showed no adverse effects. In a rat two-generation study, the NOAEL was $150 \mathrm{mg} / \mathrm{kg}$ bw/day. In 2012, this dosage was used by EFSA (NDA Panel), in association with a 200 -fold safety factor, to propose an Acceptable Daily Intake equivalent to $53 \mathrm{mg} /$ day for a $70 \mathrm{~kg}$ adult. The requested use level of $2 \mathrm{mg} /$ day was ratified by the EU Commission.
\end{abstract}

\section{Introduction}

Zeaxanthin $\left(3,3^{\prime}\right.$-dihydroxy- $\beta$-carotene, CAS number 144 $68-3$ ) is a nutritional carotenoid in a category referred to as xanthophylls. Zeaxanthin is structurally closely similar to lutein. The intake of both carotenoids in the human diet is regarded as healthy, with these components reflecting an adequate intake of fruit and vegetables.

Lutein as a human dietary supplement is often obtained as an extract from Tagetes (marigold) and the extract always contains some zeaxanthin. Zeaxanthin itself, on the other hand, tends to be produced from both biological sources and in a highly pure form synthetically. The predominant zeaxanthin stereoisomer in nature and consequently in the diet is the $3 R, 3 R^{\prime}$-stereoisomer, which is also the predominant stereoisomer of synthetic zeaxanthin (Figure 1).

In normal human food sources, lutein is more abundantly present than zeaxanthin, for example, in spinach, but there are other food sources with a relatively higher content of zeaxanthin, such as egg yolk, corn (maize), or orange pepper $[1,2]$. The usual dietary ratio of lutein : zeaxanthin is approximately $5: 1$ (Table 1) [3,4].
A closely related stereoisomer that is rarer than $3 R, 3^{\prime} \mathrm{R}$ zeaxanthin isomer in nature is the $3 \mathrm{R}, 3^{\prime} \mathrm{S}$ stereoisomer, commonly referred to as meso-zeaxanthin. This stereoisomer, like lutein and zeaxanthin, is found in the human macula and its source has been determined in primates fed with a zeaxanthin-free diet to be derived from lutein $[5,6]$.

In addition to being generally healthy and acting as antioxidants, a specific protective activity exists in the eyes of primates. In the primate eye, in the center of the retina, an area known as the macula lutea is visible as a yellow spot due to the accumulation of the macular xanthophylls. The presence of the xanthophyll carotenoids in the human appears to be physiologically significant; the concentration of xanthophylls in the macula is the highest concentration found everywhere in the primate body. Furthermore, based on filtration of potentially damaging light and quenching of photochemically induced reactive oxygen species, it is believed $[7,8]$ that, via these mechanisms, lutein, zeaxanthin, and meso-zeaxanthin may contribute to reducing the risk of Age-Related Macular Degeneration (AMD), a leading cause of irreversible loss of vision observed in western countries. 
<smiles>CC1=C(/C=C/C(C)=C/C=C/C(C)=C/C=C/C=C(C)/C=C/C=C(C)/C=C/C2=C(C)C[C@@H](O)CC2(C)C)C(C)(C)C[C@H](O)C1</smiles>

3R, $3^{\prime}$ R-zeaxanthin<smiles>CC1=C(/C=C/C(C)=C/C=C/C(C)=C/C=C/C=C(C)/C=C/C=C(C)/C=C/C2=C(C)C[C@@H](O)CC2(C)C)C(C)(C)C[C@H](O)C1</smiles>

3R, 3'S-zeaxanthin (meso-zeaxanthin)<smiles>CC1=C(/C=C/C(C)=C/C=C/C(C)=C/C=C/C=C(C)/C=C/C=C(C)/C=C/C2=C(C)C[C@H](O)CC2(C)C)C(C)(C)C[C@H](O)C1</smiles>

3S, 3'S-zeaxanthin<smiles>CC1=C[C@@H](O)CC(C)(C)[C@H]1/C=C/C(C)=C/C=C/C(C)=C/C=C/C=C(C)/C=C/C=C(C)/C=C/C1=C(C)C[C@@H](O)CC1(C)C</smiles>

$3 \mathrm{R}, 3^{\prime} \mathrm{R}, 6^{\prime} \mathrm{R}$-lutein

FIGURE 1: Structures for optical isomers of all-trans zeaxanthin and lutein.

TABLE 1: Average intake of lutein and zeaxanthin by age group (Mohamedshah et al., 1999) [3].

\begin{tabular}{lccc}
\hline Age group & $\begin{array}{c}\text { Lutein } \\
(\mu \mathrm{g} / \text { day })\end{array}$ & $\begin{array}{c}\text { Zeaxanthin } \\
(\mu \mathrm{g} / \text { day })\end{array}$ & $\begin{array}{c}\text { Lutein : Zeaxanthin } \\
\text { ratio }\end{array}$ \\
\hline $20-29$ & 745 & 178 & $4.2: 1$ \\
$30-39$ & 896 & 174 & $5.1: 1$ \\
$40-49$ & 920 & 187 & $4.9: 1$ \\
$50-59$ & 1053 & 182 & $5.8: 1$ \\
$60-69$ & 1056 & 170 & $6.2: 1$ \\
$70+$ & 990 & 170 & $5.8: 1$ \\
\hline
\end{tabular}

There is a considerable amount of safety data for zeaxanthin based mainly on routine regulatory studies with high purity synthetic zeaxanthin, manufactured by DSM Ltd. (previously manufactured by F. Hoffmann-La Roche Ltd.). A series of in vitro and in vivo tests for genotoxicity have been undertaken as well as subchronic safety studies (13 weeks in duration) by dietary exposure at high dosage levels in mice, rats and dogs. Developmental toxicity studies have been undertaken in rats and rabbits, a two-generation study was performed on the rat, and a chronic study of 52 weeks' duration was performed on Cynomolgus monkeys. ADME (absorption, distribution, metabolism, and excretion) studies have been undertaken. These studies with zeaxanthin are reviewed here.

Potentially, data for certain closely related substances may have relevance or should be taken into consideration, in the safety evaluation of zeaxanthin. The inclusion of a ferret study with the related xanthophyll, $\beta$-cryptoxanthin, on a read-across basis, to address the question if zeaxanthin consumption might have an adverse impact on cigarette smokers, is described. Reference is also made to known studies with lutein and meso-zeaxanthin.

Safety data from human intervention studies in which synthetic zeaxanthin has been supplemented, of which the AREDSII study is by far the largest, is also considered and the apparent safe level of intake from these studies compared with that derived from the animal studies.

The safety data for lutein have been evaluated by the European Food Safety Authority (EFSA). Due to the close similarity of lutein and zeaxanthin, it is probable that the toxicology for the pure substances is very similar, although it has to be remembered that within the eye a highly specific 
TABLE 2: List of genotoxicity, repeat dose, and reproductive safety studies conducted with DSM-manufactured synthetic zeaxanthin based on international regulatory study designs.

\begin{tabular}{|c|c|c|c|}
\hline Safety studies & $\begin{array}{c}\text { Formulation } \\
\text { nominal } \%\end{array}$ & Concentration or dosage & Result \\
\hline & \multicolumn{3}{|c|}{ Concentration } \\
\hline \multicolumn{4}{|l|}{ Genotoxicity in vitro } \\
\hline Ames, S. typhimurium mutation assay & Crystalline & $0,2.4-1500 \mu \mathrm{g} /$ plate & Negative \\
\hline Gene mutation in V79 cells & Crystalline & $0,1-16 \mu \mathrm{g} / \mathrm{mL}$ & Negative \\
\hline $\begin{array}{l}\text { Unscheduled DNA Synthesis (UDS) in rat } \\
\text { hepatocytes }\end{array}$ & Crystalline & $0.1-16 \mu \mathrm{g} / \mathrm{mL}$ & Negative \\
\hline \multirow[t]{2}{*}{ Human lymphocytes } & Crystalline & 0,60, and $120 \mu \mathrm{g} / \mathrm{mL}$ & Negative \\
\hline & \multicolumn{3}{|c|}{ Dose (mg/kg bw/day) } \\
\hline \multicolumn{4}{|l|}{ Genotoxicity assays in vivo } \\
\hline Mouse micronucleus & $10 \%$ beadlet & $0,44.5,89$, and 178 & Negative \\
\hline \multicolumn{4}{|l|}{ Subchronic and chronic } \\
\hline 13-week oral (admix) in mice & $10 \%$ beadlet & $0,0,250,500$, and 1000 & NOAEL, high dose \\
\hline 13-week oral (admix) in rats & $10 \%$ beadlet & $0,0,250,500$, and 1000 & NOAEL, high dose \\
\hline 13-week oral (feed cubes) in dogs & $10 \%$ beadlet & $\begin{array}{l}0,123,204 \text {, and } 422 \text { males : } 0,104,238 \text {, and } 442 \\
\text { females }\end{array}$ & NOAEL, high dose \\
\hline $\begin{array}{l}\text { 1-year oral (gavage) in monkeys } \\
\text { zeaxanthin or lutein }\end{array}$ & $10 \%$ beadlet & $0,0.2$, and 20 for zeaxanthin or lutein & NOAEL, high dose \\
\hline \multicolumn{4}{|l|}{ Reproductive studies } \\
\hline Teratology oral (admix) in rats & $10 \%$ beadlet & $0,250,500$, and 1000 & NOAEL, high dose \\
\hline Teratology oral (gavage) in rabbits & Crystalline in oil & $0,100,200$, and 400 & NOAEL, high dose \\
\hline Two-generation (admix) in rats & $10 \%$ beadlet & $0,0,50,150$, and 500 & NOAEL, inter. dose \\
\hline
\end{tabular}

biological stereoisomeric differentiation may occur. Many of the analytical methods used in the past did not differentiate zeaxanthin and lutein such that the information on the differential occurrence of lutein and zeaxanthin in fruits and vegetables for many years was incomplete. The Joint FAO (Food and Agriculture Organization of the United Nations)/WHO (World Health Organization) Expert Committee on Food Additives (JECFA) in 2006 [9] in their safety evaluation of lutein and zeaxanthin defined a "group" ADI (Acceptable Daily Intake) for lutein and zeaxanthin of 0$2 \mathrm{mg} / \mathrm{kg}$ bw/day, covering both substances.

The toxicity of compounds can often be strongly influenced by their purity. If coming from a natural source, the other natural components or contaminants (e.g., pesticides) need to be taken into consideration. If coming from chemical synthesis, a representative batch of typical purity containing the synthetic by-products that might be present needs to be tested. In the regulatory studies for zeaxanthin presented here coming from DSM Nutritional Products Ltd., the zeaxanthin tested was in accord with the manufacturer's purity specification of at least $98 \%$ zeaxanthin ( $>96 \%$ all-trans, $<2 \%$ cis). This high purity substance is marketed in a formulation designed to provide stability against oxidation and enhance bioavailability.

The DSM studies reported here have been undertaken by a number of toxicologists and safety specialists over a number of years and are described mainly in summary form. The individual study reports describe the results in detail. In the regulatory processes to obtain approval for human use, the detailed reports are supplied to the respective regulatory authority.

\section{Methods: Regulatory Animal Safety Studies with Synthetic Zeaxanthin}

An extensive array of conventional toxicology studies has been undertaken with DSM synthetic zeaxanthin (Ro 019509). The studies undertaken by DSM were for the purpose of assessing safety from oral intake, or for worker safety purposes, and are listed in Table 2.

The toxicology studies undertaken by DSM were predominantly undertaken using recognized international regulatory guidelines and, in particular, respective Organization for Economic Cooperation and Development (OECD) guidelines. The OECD guideline stipulates for each study design how the study should be performed with a detailed range of study design requirements, such as numbers of replicates or animals, the concentrations or dosages that are appropriate to ensure sufficiently stringent testing, details of the endpoints that should be investigated, and guidance on the evaluation of the data obtained.

In the case of the two-generation rat study, the key regulatory study for the overall safety assessment, the study was designed to meet the known requirements of the OECD 416 guidelines (22 January, 2001) and the US FDA Center for Food Safety and Applied Nutrition, Redbook 2000, Toxicological Principles for the Safety of Food Ingredients, IV.C.9.a. Guidelines for Reproduction Studies (20 July, 2000). 
Additionally, the studies were undertaken following the principles of Good Laboratory Practice (GLP). In the case of the two-generation rat study, the study was conducted in accordance with the OCD GLP guideline and UK GLP guidelines, as the study was conducted in UK. Analyses undertaken to confirm the stability and concentrations of zeaxanthin in the treated diet as well as analyses undertaken to assess the concentration of zeaxanthin in plasma and liver samples were performed at the DSM test site in Switzerland and performed in accordance with Swiss ordinance on GLP.

Additionally, in vivo studies were undertaken following the local national requirements on animal housing and animal welfare requirements such as in the UK, the Home Office "code of practice for the housing and care of animals used in scientific procedures."

Importantly, the evaluation of zeaxanthin involved a special study on Cynomolgus monkeys, which included a range of specific endpoints to investigate safety to the primate and human eye. The Cynomolgus monkey has been shown to be an excellent model to investigate the induction and dose dependency of canthaxanthin crystal formation in the retina [10-13]. Using similar procedures as described in these publications, the study included indirect ophthalmoscopic examinations performed using the Bonnoskop and direct ophthalmoscope and a contact lens biomicroscope. Additional evaluations were performed using the ophthalmic slit lamp biomicroscope in combination with wide-field corneal contact fundus lenses. Electroretinography (ERG) was undertaken at intervals during the study. Terminal eye pathology involved evaluation of whole-mounts of retinas from the right eyes by microscopic investigation with light or confocal microscopy. Maculas were investigated under the polarization microscope and semiquantitative analysis of inclusions was performed. Routine histopathological investigation of paraffin sections from retinal periphery was performed and zeaxanthin and lutein in the retina and lens were measured analytically by High-Performance Liquid Chromatography (HPLC).

\section{Results}

\subsection{Genotoxicity Studies}

3.1.1. S. typhimurium Mutagenicity (Ames) Test, OECD 471. Crystalline zeaxanthin was evaluated for mutagenic activity in the Ames assay using the plate incorporation and the preincubation method. Seven Salmonella typhimurium standard tester strains were employed (TA1535, TA1537, TA1538, TA97, TA98, TA100, and TA102) with and without an exogenous metabolic activating enzyme system ( $\mathrm{S} 9$-mix) derived from livers of phenobarbital $/ \beta$-naphthoflavone treated male rats. Due to the strong precipitation of the test compound in the aqueous medium, $1500 \mu \mathrm{g} /$ plate was chosen as the highest dose level. There was no increase of the numbers of mutants in any of the tester strains, while the positive controls verified the sensitivity of the strains and the activity of the S9-mix [14].

In one very early laboratory batch of pure crystalline zeaxanthin, a positive result was found in the Ames test. It was determined that pure zeaxanthin is not mutagenic; however, degradation products formed during exposure of crystalline zeaxanthin to air and light were considered responsible for the mutagenic activity [15]. In addition, it was determined that components in the beadlet formulation scavenged the mutagenic activity of degraded crystalline zeaxanthin, thus further protecting against the occurrence of mutagenic activity. The beadlet formulation for the marketed product includes the antioxidants (ascorbyl palmitate, sodium ascorbate, and $d l-\alpha$-tocopherol), which prevent degradation.

Crystalline zeaxanthin that had been kept in storage beyond the maximum shelf life was subsequently assessed in a non-GLP Ames test [16]. The purpose of this study was to confirm the absence of mutagenic activity of crystalline zeaxanthin. Five Salmonella typhimurium tester strains (TA1535, TA97, TA98, TA100, and TA102) were employed with and without metabolic activation (S9-mix). No relevant increase in the number of revertant colonies was apparent and it was concluded that neither zeaxanthin nor any of the metabolites formed by the metabolic activation system was mutagenic in the Ames test.

3.1.2. Gene Mutation Assay in V79/HGPRT Cells, OECD 476. In the gene mutation assay in cultured mammalian cells, zeaxanthin was tested for its ability to induce gene mutations at the HGPRT (Hypoxanthine Guanine Phosphoribosyl Transferase) locus in the established cell line V79, derived from Chinese hamster lung cells. Treatment with $1 \mu \mathrm{g}$ to $16 \mu \mathrm{g} / \mathrm{mL}(0.002-0.03 \mathrm{mmol} / \mathrm{L})$ did not induce mutations to 6-thioguanine resistance in V79 cells in vitro, neither in the absence nor in the presence of a rat liver activation system [17].

3.1.3. Unscheduled DNA Synthesis (UDS) Assay, OECD 482. The ability of zeaxanthin to induce DNA damage was tested by the Unscheduled DNA Synthesis assay (UDS test) as measured by the incorporation of radiolabeled nucleotides into nonreplicated DNA of freshly isolated rat hepatocytes. A 20-hour exposure to $1 \mu \mathrm{g}$ to $16 \mu \mathrm{g}$ zeaxanthin per $\mathrm{mL}$ did not induce DNA repair synthesis in primary cultures of rat hepatocytes [18].

3.1.4. Chromosome Analysis of Human Peripheral Lymphocytes, OECD 473. The potential in vitro clastogenic activity of zeaxanthin was assessed using human peripheral blood lymphocytes as target cells in the presence and absence of rat liver activating enzyme system (S9-mix). Under the experimental conditions described, neither zeaxanthin nor any of its metabolites induced chromosomal aberrations in human peripheral blood lymphocytes [19].

3.1.5. Mouse Micronucleus Assay, OECD 474. Zeaxanthin was tested in the in vivo micronucleus assay in mice. Zeaxanthin, $10 \%$ beadlet formulation, was administered orally at dose levels of $44.5,89.0$, and $178 \mathrm{mg} / \mathrm{kg}$ of zeaxanthin 30 and 6 hours prior to sacrifice. There was no increase of micronuclei; thus, it was concluded that under the conditions of the study zeaxanthin did not induce chromosome breaks or mitotic nondisjunctions in mouse bone marrow cells at doses up to $178 \mathrm{mg} / \mathrm{kg}$ of zeaxanthin [20]. 


\subsection{Short-Term Toxicity Studies}

3.2.1. Acute Safety Studies, Pre-OECD Guideline, Similarities to Guideline OECD 401. Acute studies with zeaxanthin were performed in rats and mice. Zeaxanthin has a low order of acute toxicity. All mice and rats survived a single oral dose of up to $4000 \mathrm{mg} / \mathrm{kg}$ in rats and $8000 \mathrm{mg} / \mathrm{kg}$ in mice. The $\mathrm{LD}_{50}$ values in rats and mice, therefore, were greater than 4000 and $8000 \mathrm{mg} / \mathrm{kg}$ body weight, respectively [21].

3.2.2. Guinea Pig Skin Sensitization Test, OECD 406. An optimization test (according to Maurer) was performed with zeaxanthin in albino guinea pigs of both sexes. No signs of skin irritation or sensitization were observed [22]. A subsequent maximization test in albino guinea pigs, based on OECD guideline 406, was also negative [23].

3.2.3. Rabbit Irritation Test, OECD 405. The primary eye irritation potential of zeaxanthin was studied in young adult rabbits [24]. The risk that an accidental or occasional ocular exposure to zeaxanthin could cause injury to the eye in man was considered to be low.

\subsection{General Toxicology Studies}

3.3.1. Subchronic Safety Studies. 13-week subchronic toxicity studies have been performed with synthetic zeaxanthin in three species, mouse, rat, and dog. Preliminary studies (5and 10-day studies) were conducted beforehand to ensure appropriate selection of dosages for the main studies.

3.3.2. 13-Week Study in Mice, Similar to OECD 408. A 13week oral safety study was performed in mice with a $9.3 \%$ beadlet formulation of zeaxanthin, administered as a feed admixture. Groups of 10 male and 10 female mice were treated with $0,250,500$, and $1000 \mathrm{mg} / \mathrm{kg}$ body weight/day ( $\mathrm{mg} / \mathrm{kg}$ bw/day) of zeaxanthin. The placebo beadlets were added to the diet so that all 4 groups received similar amounts of beadlets. There was no treatment-related hematology or clinical chemistry findings. No discoloration of adipose tissue or other findings were observed at necropsy and there were no histopathological effects attributable to zeaxanthin or the beadlet formulations. The No Observed Adverse Effect Level (NOAEL) of zeaxanthin was $>1000 \mathrm{mg} / \mathrm{kg}$ bw/day in mice [25].

In line with the respective OECD guideline procedures for mice, the study did not include ophthalmoscopy, although histopathology of the eyes was undertaken.

3.3.3. 13-Week Study in Rats, OECD 408. An original 13-week oral safety study was conducted in rats with a $9.3 \%$ beadlet formulation of zeaxanthin administered as a feed admixture. Groups of 16 male and 16 female rats were treated with 0 , 250,500 , and $1000 \mathrm{mg} / \mathrm{bw} /$ day of zeaxanthin. The NOAEL for zeaxanthin was $>1000 \mathrm{mg} / \mathrm{kg}$ bw/day in rats [26].

Due to a change in manufacturing process, a second 13 week oral safety study in rats was performed with a $10 \%$ beadlet formulation of zeaxanthin from an updated process. Groups of 16 male and 16 female rats were treated with doses of $0,250,500$, and $1000 \mathrm{mg} / \mathrm{kg}$ bw/day of zeaxanthin as a dietary admixture [27]. All groups received similar amounts of beadlets, by adjusting the diet with control beadlets. There was no effect of treatment on food intake and body weight. Yellow-orange discoloration of the feces was seen in all zeaxanthin-treated rats, especially at the high dose. No treatment-related changes in hematological and clinical chemistry parameters were observed. Urine $\mathrm{pH}$ values were slightly decreased in male rats of all dose groups. In line with the respective OECD guideline, the study included ophthalmoscopic evaluations. About 20-30 minutes prior to examination, a mydriatic was instilled into each eye of control and high-dose animals. The examinations were made using a "KEELER" Fison binocular ophthalmoscope. There were no treatment-related changes.

At necropsy, a slight orange discoloration of the adipose tissue was reported in all treated animals; however, this was not considered an adverse effect but due to color of the test compound. There were no treatment-related changes in organ weights or histopathological findings. Under the conditions of this study, the NOAEL in this second rat study was again $>1000 \mathrm{mg} / \mathrm{kg}$ bw/day.

3.3.4. 13-Week Dog Study, Similar to OECD 409. A 13-week safety study in dogs was conducted with a $9.4 \%$ beadlet formulation of zeaxanthin. Zeaxanthin beadlets were incorporated into feed pellets and fed to groups of 3 male and 3 female beagle dogs to achieve a dose of zeaxanthin of 0 , 123,204 , and $422 \mathrm{mg} / \mathrm{kg}$ bw/day (males) and $0,104,238$, and $442 \mathrm{mg} / \mathrm{kg}$ bw/day (females). This corresponds to test article concentrations in feed of $0,4,8$, and $16 \%$, respectively. Control beadlets were added so that the amount of beadlets present in the feed cubes was similar for all groups.

No treatment-related toxicity was observed throughout the study. The test article was found to strongly discolor and to slightly soften the feces, particularly in the highdose group. Ophthalmoscopic evaluations were undertaken at day and at the end of week 13. Following induction of mydriasis, eyes including cornea, chambers, lens, and retina of all dogs were examined using a fundus-camera KOWA $\mathrm{RC}-2$. The central parts of the retina (generally including the optic disc) were recorded on an Ektachrome-X film. No treatment-related findings were reported. Urinalysis as well as hematological and serum clinical chemistry investigations showed no treatment-related effects. At necropsy, male dogs from the mid- and high-dose groups showed slight to moderate discoloration (yellow to reddish) in the adipose tissue, which was considered not an adverse effect and probably reflected presence of zeaxanthin. There were no treatmentrelated histopathological findings. The NOAEL in this study was $>422 \mathrm{mg} / \mathrm{kg}$ bw/day [28].

\subsection{Reproductive Safety Studies}

3.4.1. Developmental Toxicity Study in Rats, OECD 414. In a developmental toxicity study in rats, zeaxanthin $(10 \%$ beadlet formulation) was administered at doses of 0,250 , 500 , and $1000 \mathrm{mg} / \mathrm{kg}$ bw/day orally as a feed admixture from day 7 through day 16 of gestation [29]. A subgroup was 
TABLE 3: Effects on reproduction data in the zeaxanthin two-generation study in rats [31].

\begin{tabular}{|c|c|c|c|c|c|}
\hline Nominal dosage (mg/kg bw/day) & 0 & $\begin{array}{c}0 \\
\text { (placebo) }\end{array}$ & 50 & 150 & 500 \\
\hline \multicolumn{6}{|l|}{$\mathrm{F}_{1}$ generation } \\
\hline Adults, mating index \% & 100.0 & 100.0 & 96.0 & 96.0 & $79.3^{*} F$ \\
\hline \multicolumn{6}{|l|}{ Mean number of pups: } \\
\hline born & 10.2 & 10.9 & 10.7 & 10.7 & 9.7 \\
\hline $\begin{array}{l}\text { alive day } 4 \text { postpartum } \\
\text { (before culling) }\end{array}$ & 10.0 & 10.9 & 10.5 & 10.5 & 9.7 \\
\hline \multicolumn{6}{|l|}{ P generation } \\
\hline \multicolumn{6}{|l|}{$\%$ pup weight gain } \\
\hline Days 4-7 postpartum & 62.3 & 62.0 & 64.2 & 61.6 & 59.3 \\
\hline Days 1-21 postpartum & 774.7 & 753.3 & 780.9 & 755.0 & $725.3^{* *} J$ \\
\hline \multicolumn{6}{|l|}{$\mathrm{F}_{1}$ generation } \\
\hline \multicolumn{6}{|l|}{$\%$ pup weight gain } \\
\hline Days 4-7 postpartum & 64.4 & 62.8 & 60.5 & 61.3 & $58.1^{*} J$ \\
\hline Days 1-21 postpartum & 738.9 & 745.1 & 713.5 & 724.9 & 695.0 \\
\hline
\end{tabular}

Caesarian-sectioned on day 21 of gestation and a rearing subgroup was allowed to deliver naturally and was observed up to day 23 of lactation. There was no indication of any embryotoxic or teratogenic action of zeaxanthin in any of the treated groups. The rearing subgroup showed no indication of any functional abnormalities in the treated groups. It was concluded that, under the conditions of this study, zeaxanthin was neither embryotoxic nor teratogenic in rats at doses up to $1000 \mathrm{mg} / \mathrm{kg}$ bw/day.

3.4.2. Developmental Toxicity Study in Rabbits, OECD 414. In a developmental toxicity study in rabbits, zeaxanthin was administered at doses of $0,100,200$, and $400 \mathrm{mg} / \mathrm{kg}$ bw/day orally in rapeseed oil from day 7 through day 19 of gestation. Rabbits were Caesarian-sectioned on day 30 of gestation [30]. No deaths or signs of maternal toxicity were observed in the treated groups. There was no indication of any embryotoxic or teratogenic action of zeaxanthin in the treated groups. There were some isolated malformations among the groups, including controls, but there was no evidence of any treatment-related effect. It was concluded that, under the conditions of this study, zeaxanthin was neither embryotoxic nor teratogenic in rabbits at doses up to $400 \mathrm{mg} / \mathrm{kg}$ bw/day.

3.4.3. Two-Generation Study in Rats, OECD 416. A twogeneration study was performed with synthetic zeaxanthin in rats [31]. Multigeneration studies involve exposure to test compounds beginning before mating, continuing during mating, and throughout gestation and lactation, until weaning, and cover all reproductive life phases over two generations. There was a range of developmental and behavioral testing in addition to reproduction endpoints. Ophthalmologic examination is not part of the OECD 416 guideline study requirements but testing on the young rats included confirmation of the pupillary reflex response and corneal tactile response.

In the two-generation study, DSM-manufactured zeaxanthin was administered in the diet at nominal doses of 0 (control diet), 0 (placebo beadlet control), 50, 150, and $500 \mathrm{mg} / \mathrm{kg}$ bw/day active ingredient, by admixture of $10 \% \mathrm{WS}$ beadlets to the feed. Although zeaxanthin in a 13-week toxicity study in the rat was well tolerated at $1000 \mathrm{mg} / \mathrm{kg}$ bw/day, to achieve a dose level of $1000 \mathrm{mg} / \mathrm{kg} / \mathrm{day}$, the beadlet concentration in the diet approached $20 \%$. The high-dose level $500 \mathrm{mg} / \mathrm{kg}$ bw/day was selected on the basis of avoiding potential nutritional imbalance due to the high beadlet content in the diet over the duration of a two-generation study. Two control groups received either the control diet only or placebo beadlets incorporated in the diet at the same concentrations as the zeaxanthin beadlets in the high-dose group. The parental $(\mathrm{P})$ generation females were allowed to litter and rear their offspring to weaning. Young were randomly selected from each group to form the filial $\left(F_{1}\right)$ generation.

Administration of $500 \mathrm{mg} / \mathrm{kg}$ bw/day zeaxanthin active ingredient to rats for two successive generations produced marginal adult toxicity in terms of slightly lower food intake during the lactation period of the $\mathrm{P}$ generation, a slightly lower body weight gain during the gestation period of the $\mathrm{F}_{1}$ generation, and a possible, slight, adverse effect on fertility of the $\mathrm{F}_{1}$ generation with a lower mating index (mating index is the number of females with determined copulations/number of oestrous cycles required for their insemination $\times 100)$ and slightly fewer pups were born (Table 3 ). At this dosage in both generations, percentage of pup growth during lactation was also slightly lower than in the control groups (Table 3 ).

Samples of plasma and liver from the $\mathrm{P}$ and $\mathrm{F}_{1}$ generation adults and pups were analysed for zeaxanthin exposure monitoring. The analysis results showed that exposure was 
TABLE 4: Plasma and liver concentration of zeaxanthin in adults and weanlings in the two-generation study in rats [31].

\begin{tabular}{|c|c|c|c|c|c|}
\hline \multicolumn{6}{|c|}{$\begin{array}{l}\text { Zeaxanthin concentration }(\mu / \mathrm{L} \text { or } \mu / \mathrm{kg}) \text { at nominal dosage } \\
(\mathrm{mg} / \mathrm{kg} \text { bw/day })\end{array}$} \\
\hline Dosage & 0 & 0 & 50 & 150 & 500 \\
\hline \multicolumn{6}{|c|}{ Pgeneration } \\
\hline \multicolumn{6}{|c|}{ Plasma,$\mu / L$} \\
\hline \multicolumn{6}{|c|}{ Adults } \\
\hline Male & - & - & 24 & 47 & 111 \\
\hline Female & - & - & 19 & 29 & 71 \\
\hline Weanlings & - & - & 61 & 127 & 353 \\
\hline \multicolumn{6}{|l|}{ Liver, $\mu / \mathrm{kg}$} \\
\hline \multicolumn{6}{|l|}{ Adults } \\
\hline Male & 14 & - & 599 & 1121 & 2581 \\
\hline Female & 4 & 5 & 1147 & 1992 & 3159 \\
\hline Weanlings & - & - & 4015 & 10892 & 23836 \\
\hline \multicolumn{6}{|c|}{$F_{1}$ generation } \\
\hline \multicolumn{6}{|c|}{ Plasma, $\mu / L$} \\
\hline \multicolumn{6}{|c|}{ Adults } \\
\hline Male & - & - & 22 & 42 & 109 \\
\hline Female & - & - & 20 & 42 & 87 \\
\hline Weanlings & - & - & 52 & 85 & 213 \\
\hline \multicolumn{6}{|l|}{ Liver, $\mu / \mathrm{kg}$} \\
\hline \multicolumn{6}{|l|}{ Adults } \\
\hline Male & - & - & 114 & 645 & 1689 \\
\hline Female & 11 & - & 1077 & 1382 & 3785 \\
\hline Weanlings & - & 11 & 4313 & 7904 & 21611 \\
\hline
\end{tabular}

essentially similar in the $\mathrm{P}$ and $\mathrm{F}_{1}$ generations. Higher plasma concentrations and notably higher liver concentrations were observed in the weanling pups at day 21 postpartum compared to the adults of the corresponding treatment group (Table 4). Exposure increased with increasing dose although it was not proportional to dose. The higher exposure in the 21day-old pups probably reflects intake through the maternal milk and that they had already started eating the treated diet provided to the mothers. The relative concentrations in the liver in comparison to concentrations in the plasma were notably higher, in both adults and weanlings (Table 4), suggesting these are accumulation in the liver. However, the high accumulation in the liver of weanlings (3 weeks of age) clearly diminished during subsequent rearing and as adults of the $\mathrm{F}_{1}$ generation showed similar tissue concentrations to the P generation, which was exposed from 6 weeks of age.

In conclusion, the NOAEL was defined as the nominal dosage of $150 \mathrm{mg}$ zeaxanthin/kg bw/day.

3.5. Chronic Rodent Carcinogenicity Studies. No carcinogenicity studies are available for zeaxanthin, or for lutein. Genotoxicity studies were negative and histological examinations of tissues from repeat dose toxicity studies have not shown any preneoplastic effects or indeed no indication of histological effects at all.
There is data for two carotenoids (canthaxanthin and astaxanthin) showing that chronic administration over two years in rats, but not mice, induces liver toxicity. These two carotenoids induce liver enzyme including cytochrome P450 enzyme CYP1A in the rat $[32,33]$, although not in the mouse [34] and not in vitro in human hepatocytes [35]. However, lutein did not affect phase-I or phase-II liver enzyme activities in the rat [32]. Due to its close isomeric relationship to lutein, it is considered unlikely that zeaxanthin is a liver enzyme inducer.

In 2010, EFSA applied an additional safety factor of 2 in the ADI calculations for lutein [36] and in 2012 for zeaxanthin [37] to take account of the absence of chronic rodent studies.

3.6. ADME (Absorption, Distribution, Metabolism, and Excretion) Studies. Metabolism studies, or ADME studies, are a useful component of safety testing as the provided information on the metabolism and kinetics of a substance and, when human data is available, on human relevance.

3.6.1. Balance Study in Rats. A distribution study with $\left({ }^{14} \mathrm{C}\right)$ zeaxanthin was performed in male rats, after a pretreatment feeding with zeaxanthin-poor or zeaxanthin-enriched diet $(0.001 \%$ in feed $)$ and subsequent single dose administration of $\left({ }^{14} \mathrm{C}\right)$-zeaxanthin in a liposomal preparation. One day after dosing, approximately two-thirds of the administered radioactivity was excreted in feces and urine and approximately $1 / 3$ of the administered radioactivity was present in the body and GI-tract. The pattern of distribution in the tissues and excretion was similar for rats prefed with zeaxanthinpoor and those fed with zeaxanthin-enriched diet. After 1 week, less than $1 \%$ of the administered radioactivity was in the body and the digestive tract. The amount of radioactivity absorbed and excreted in the urine tended to be lower for animals fed with the zeaxanthin-poor diet. It was concluded that the radioactivity from $\left({ }^{14} \mathrm{C}\right)$-zeaxanthin is rapidly depleted from the body and the GI-tract of rats [38].

3.6.2. Distribution Study in Rats. A study was performed to investigate zeaxanthin distribution in rats fed with a zeaxanthin $5 \%$ beadlet formulation-enriched diet. Male rats received a diet containing $10 \mathrm{mg}$ or $100 \mathrm{mg}$ zeaxanthin $/ \mathrm{kg}$ feed (approximately $0.8 \mathrm{mg}$ or $8 \mathrm{mg} / \mathrm{kg}$ bw/day) for five weeks. A dose-dependent accumulation of zeaxanthin was found in various tissues with the highest concentrations in the small intestine and spleen, followed by liver, fat, and adrenal glands. The thyroid gland and the eye levels were below the levels of detection. There was a marked decrease of zeaxanthin concentration during a subsequent 5 -week reversibility period [39].

3.6.3. Radioactivity in Expired Air, Mass Balance Study. In balance studies with a liposomal preparation of $\left({ }^{14} \mathrm{C}\right)$ zeaxanthin in male rats, about $1 \%$ of the administered dose, that is, about $4 \%$ to $7 \%$ of the absorbed dose, was measured in the expired air during the first 24 hours after administration. Contribution of respiration in the excretion of radioactivity was considerably higher in the case of zeaxanthin when 


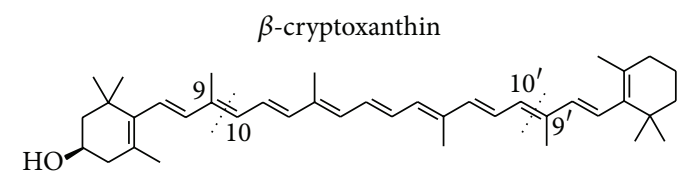<smiles>CC1=C(/C=C/C=C/C(C)=C/C=C(C)/C=C/C=C(C)/C=C/C=C(C)/C=C/C2=C(C)CC(O)CC2(C)C)C(C)(C)CC(O)C1</smiles><smiles>CCOC(C)=O</smiles>

3-OH- $\beta$-apo- $10^{\prime}$-carotenal<smiles>CC(=O)/C=C/C1=C(C)CCCC1(C)C</smiles>

$\beta$-ionone

Zeaxanthin<smiles>CC(=O)/C=C/C1=C(C)CC(O)CC1(C)C</smiles>

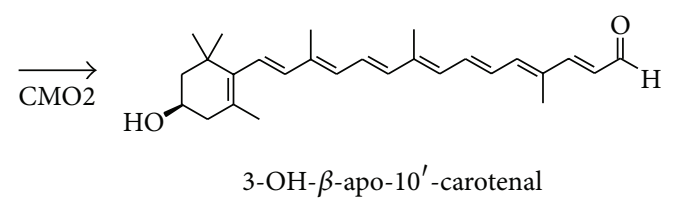<smiles>CC(=O)/C=C/C1=C(C)CC(O)CC1(C)C</smiles>

3-OH- $\beta$-ionone

FIGURE 2: Xanthophyll carotenoids $\beta$-cryptoxanthin and zeaxanthin, and the metabolites from CMO2 cleavage, in ferrets (adapted from Mein et al., 2011) [42].

compared to previous studies with astaxanthin and canthaxanthin. Absorption (biliary excretion not considered) varied from around $10 \%$ to around $20 \%[38,40]$.

3.6.4. Metabolite Studies. It is known that $\beta$-carotene is metabolised by central cleavage by the enzyme $\beta, \beta$-carotene$15,15^{\prime}$-monooxygenase (CMO1). On the other hand, the nonprovitamin A xanthophylls, lutein, and zeaxanthin are metabolised preferentially by eccentric cleavage by carotene9, 10-monooxygenase (CMO2), alternatively known as $\beta$ carotene oxygenase 2 (BCO2). $\beta$-Cryptoxanthin is also metabolised eccentrically through CMO2, which has been identified in humans, mice, and ferrets [41].

The metabolite pathways of lutein, zeaxanthin, and $\beta$ cryptoxanthin have been published in 2011 [42]. In this publication, the production of apocarotenoids from $\mathrm{CMO} 2$ metabolism in ferrets was shown for all of these three xanthophylls. All three are cleaved at the 9,10 position as well as at $9^{\prime}, 10^{\prime}$. This gives rise to four metabolites for both lutein and $\beta$-cryptoxanthin. Zeaxanthin however is symmetrical such that there are only two metabolites, 3$\mathrm{OH}-\beta$-apo- $10^{\prime}$-carotenal and $3-\mathrm{OH}-\beta$-ionone. Both of these metabolites are derived from eccentric cleavage of lutein and $\beta$-cryptoxanthin (Figure 2 ). As zeaxanthin has the same ring structure at each end of the molecule, the same two metabolites are produced irrespective of whether cleavage occurs at the 9,10 position or the $9^{\prime}, 10^{\prime}$ position.

In addition to cleavage reaction products, there is evidence of a common metabolite from both lutein and zeaxanthin from noncleavage metabolism. In a human study with zeaxanthin, the metabolite all-E- $3^{\prime}$-dehydro-lutein was formed; under normal dietary conditions, all-E- $3^{\prime}$-dehydrolutein is predominantly formed from other sources, most likely from lutein, rather than from dietary zeaxanthin [43].

Further, using chiral-phase HPLC, two diastereoisomers, $\left(3 \mathrm{R}, 6^{\prime} \mathrm{R}\right)-3^{\prime}$-dehydro-lutein and $\left(3 \mathrm{R}, 6^{\prime} \mathrm{S}\right)-3^{\prime}$-dehydro-lutein, were identified and shown to be common metabolites of lutein and zeaxanthin in rhesus monkeys [5].

\subsection{Special Toxicological Studies}

3.7.1. One-Year Chronic Study in Monkeys. Safety studies are not normally undertaken in monkeys, at least not for nutritional substances. However, a known profile of human response that has been observed in the past in humans, with high intake of the carotenoid canthaxanthin, is accumulation in the eye and for the so-called "canthaxanthin retinopathy" [10]. Therefore, a chronic study was undertaken in monkeys with the purpose to assess the chronic safety of zeaxanthin and lutein in primates and to determine the potential for crystal formation in the retina. There are morphological differences in the structure of the eye between rodents and primates and further investigation in primates was considered important. There is no specific OECD guideline for the study design undertaken, which was designed taking into account general requirements for primate safety studies.

The chronic study performed in Cynomolgus monkeys was 52 weeks in duration and was an investigation for zeaxanthin and also for lutein (each with separate groups). $10 \%$ beadlet formulations of both substances were used. Oral doses of 0.2 and $20 \mathrm{mg} / \mathrm{kg}$ bw/day of zeaxanthin or lutein were given respectively by gavage to groups of 2 male and 2 female monkeys. For both $20 \mathrm{mg} / \mathrm{kg}$ bw/day groups, one additional male and female were sacrificed after 6 months of treatment. Normal toxicological endpoints were included as well as specific endpoints for the eyes.

All monkeys survived the treatment period. There were no clinical signs of toxicity and there was no effect of treatment on overall mean body weight gain or group mean food intake. At the high dose of zeaxanthin, orange-yellow coloration of the feces was observed during the treatment period and, at necropsy, yellow discoloration of adipose tissue was observed. These were considered as coloration 
changes from the presence of the test compound and were not considered an adverse effect. There were no changes in ECG or blood pressure data, considered to be related to zeaxanthin treatment. There were no treatment-related changes in urine, hematological, and serum clinical chemistry parameters. At necropsy, there were no abnormal gross findings or organ weight change. There were no treatment-related histopathological findings.

A comprehensive examination of the eyes of treated monkeys was performed which included ophthalmoscopy and biomicroscopy examinations, fundus photography, and electroretinography (ERG). Postmortem examinations of the retina of the right eye included macroscopic inspection, microscopic pathology under polarized and bright light, for peripheral retina and macula, confocal microscopy of macula, and histopathological examination of the peripheral retina. A determination of lutein and zeaxanthin in retina and lens of the left eye was performed by HPLC. These procedures and results are described in more detail.

Ophthalmic Examinations. Ophthalmic examinations were performed on the monkeys by two independent examiners. Indirect ophthalmoscopic examinations were performed using the Bonnoskop and direct ophthalmoscope and a contact lens biomicroscope. Overall, based on the ophthalmic examination findings, it was concluded that there were no adverse findings that were considered to be related to treatment and there was no evidence for crystalline deposits in the retina of treated monkeys $[44,45]$.

Additional evaluations were performed using the ophthalmic slit lamp biomicroscope in combination with widefield corneal contact fundus lenses. The results of these examinations showed that there were no crystalline deposits or inclusions similar to those that have been seen in humans or in Cynomolgus monkeys ingesting high dosages of the carotenoid, canthaxanthin. There were some retinal findings often seen in the human- and nonhuman-primate retina; however, none of these were considered to be related to treatment $[44,45]$. The polarising structures that were observed were found not only in the zeaxanthin- and lutein-treated monkeys, but also in the control monkeys. The implication of the special eye examinations included into the 52-week monkey study is considered to be that even for high intake zeaxanthin or lutein consumers; there is no indication that crystalline deposits could develop in the retina, as was seen in man and monkeys with high-dose canthaxanthin supplementation.

Electroretinography (ERG). ERG was performed in all animals once predose and during weeks 25 to 26 , weeks 38 to 39 , and weeks 51 to 52 of treatment. There were no treatmentrelated effects in electroretinograms, which is considered a sensitive procedure to detect early signs of generalized retinal degeneration [46].

Eye Pathology. Whole-mounts of retinas from the right eyes were used for microscopic investigations with light or confocal microscopy. Maculas were punched out with a $7 \mathrm{~mm}$ trephine before mounting them on slides and the peripheral remaining parts of the retinas were flat-mounted and investigated under the polarization microscope separately. Semiquantitative analysis of inclusions was performed by screening the flat-mounted retinas of the right eyes under polarized light using a Zeiss Axioplan. In addition, all maculas were investigated using a confocal microscopic system. Routine histopathology of paraffin sections from retinal periphery was performed [44, 45, 47]. The routine histopathological investigation of paraffin sections from retinal periphery did not show any differences between treated or control animals.

It was concluded that there were no treatment-related adverse changes in the eyes noted under the conditions of this study. Polarizing inclusions were observed in the macula of monkeys, which were not related to zeaxanthin nor lutein treatment. The incidence and grade of the inclusions in the maculas of the monkeys were not treatment or dose related. The inclusions clearly differed from crystals observed after long-term treatment at high doses of canthaxanthin. In the case of canthaxanthin, crystals were strongly dosedependent, occurred predominantly in the peripheral retina, and exhibited crystalloid morphology and larger size [12]. In contrast, inclusions in the current study were restricted to the fovea, were very small, and showed no typical crystalline morphology. The nature of the observed polarizing structures remains unknown. Since they were also observed in control animals with a naturally yellow macula, a physiological function may be hypothesized [48].

Zeaxanthin and Lutein Determinations in Retina and Lens by HPLC. Determination of lutein and zeaxanthin in retina and lens was made using HPLC. Treatment with lutein resulted in a dose-related increase of lutein in central retina, peripheral retina, and lens. In addition, after treatment with lutein at both dose levels, elevated amounts of zeaxanthin were observed in the central retina. This finding may be due to the residual zeaxanthin content in the lutein test article. Zeaxanthin levels in peripheral retina and lens were similar to those observed in the placebo group [49].

Treatment with zeaxanthin resulted in a dose-related increase of zeaxanthin in the peripheral retina. In central retina and lens, zeaxanthin content was markedly increased in animals of the high-dose group. Levels in the low dose group were comparable to those determined in the placebo group. In animals treated with zeaxanthin, lutein content was in the same order of magnitude as in the placebo group [49].

Variability of individual animal lutein and zeaxanthin content was considerable in all tissues investigated for both sexes and at all dose levels including the placebo group. Considering the variability, there was no significant difference between sexes. In addition, no relevant difference was observed in animals sacrificed in week 26 and animals sacrificed at the end of the treatment period. This suggests that steady state conditions were reached before week 26 in all eye segments investigated.

Overall, there were no clinical and no morphological evidence for treatment-related adverse changes in the eyes of Cynomolgus monkeys during or after 52 weeks of treatment with zeaxanthin or lutein, both as a $10 \%$ beadlet formulation. Specifically, there was no evidence for crystal formation in 
the eyes of treated monkeys. The NOAEL for lutein and for zeaxanthin was the highest dosage, $20 \mathrm{mg} / \mathrm{kg}$ bw/day.

3.7.2. Other Monkey Studies. There is a published study with female rhesus macaques (5/group) exposed to $10 \mathrm{mg} /$ $\mathrm{kg}$ bw/day of lutein supplements providing $9.34 \mathrm{mg}$ lutein and $0.66 \mathrm{mg}$ zeaxanthin, $10 \mathrm{mg} / \mathrm{kg}$ bw/day of zeaxanthin supplements, or supplements of a combination of lutein and zeaxanthin (each at $0.5 \mathrm{mg} / \mathrm{kg}$ bw/day) for 12 months [50]. After 12 months, one control animal, two lutein-treated animals, two zeaxanthin-treated animals, and all lutein and zeaxanthin combined-treated animals were killed. The other animals were kept under observation for six additional months without receiving further supplementation and were then killed. Plasma and ocular carotenoid analyses, fundus photography, and retina histopathology were performed on the animals.

Supplementation of female rhesus macaques with $9.34 \mathrm{mg}$ lutein/kg bw/day or $10 \mathrm{mg}$ zeaxanthin/kg bw/day for 12 months resulted in 3.2-fold and 3.7-fold increases in the mean concentrations of lutein and 4.0-fold and 4.3fold increases in the mean concentrations of zeaxanthin, in plasma and retina, respectively. Supplementation of monkeys with lutein or zeaxanthin for one year at a dose of approximately $10 \mathrm{mg} / \mathrm{kg}$ bw/day did not cause ocular toxicity and had no effect on biomarkers associated with nephrotoxicity.

3.8. Inhalation Study in Ferrets. No carcinogenic hazard is expected from direct intake of zeaxanthin or lutein. There has been a question as to whether these xanthophylls might exacerbate the risk of lung tumors in heavy smokers as was indicated to occur in two human intervention studies with high dosages of $\beta$-carotene $[51,52]$. It has been established that this exacerbating influence of $\beta$-carotene could be mimicked in the ferret [53], a species selected on the basis of metabolic considerations and certain similarities to man. Ferrets show a weak central (CMO1) cleavage of $\beta$-carotene in a similar way to humans. In contrast, rats show a much stronger CMO1 activity and a greater propensity to centrally split beta-carotene, which raised doubts about the relevance of the rat as a suitable human model.

This concern of a possible adverse influence in combination with smoking can potentially be addressed for zeaxanthin using a published study in ferrets treated with $\beta$ cryptoxanthin and exposed to cigarette smoke [54]. Zeaxanthin itself has not been tested in the ferret model. Structurally, zeaxanthin is closely related to $\beta$-cryptoxanthin. As described previously, the metabolites of zeaxanthin central cleavage, 3$\mathrm{OH}-\beta$-apo- $10^{\prime}$-carotenal and $3-\mathrm{OH}-\beta$-ionone (Figure 2 ), are also metabolites of $\beta$-cryptoxanthin central cleavage. From this overlap of CMO2 metabolites and as CMO1 in the lung of man and the ferret is not the predominant cleavage enzyme, data from the $\beta$-cryptoxanthin study can contribute to zeaxanthin evaluation on a "read-across" basis.

In this $\beta$-cryptoxanthin study, both the low and high dose lowered the incidence of cigarette smoke-induced lung squamous metaplasia. The reduction was significant for the high dose $(p=0.015,1 / 6$ ferrets affected) and was marginally significant for the low dose $(p=0.06,2 / 6$ ferrets affected), compared to the control (6/6 ferrets affected). Further, the expression of proinflammatory markers TNF $\alpha$ (expression of which was tremendously increased in smoke exposed ferret lungs) and of NF- $\kappa \mathrm{B}$ was lowered by $\beta$-cryptoxanthin administration, with stronger beneficial effects for high-dose $\beta$-cryptoxanthin than for the low-dose $\beta$-cryptoxanthin.

However, the usefulness of this read-across approach was limited by the dose selection in the $\beta$-cryptoxanthin ferret study. The dosages of $\beta$-cryptoxanthin used $(7.5 \mu \mathrm{g} / \mathrm{kg}$ and $37.5 \mu \mathrm{g} / \mathrm{kg}$ bw/day) were based on equivalence to an average American intake of $104 \mu \mathrm{g} /$ day (approximately $1.5 \mu \mathrm{g} / \mathrm{kg} \mathrm{bw} /$ day for a $70 \mathrm{~kg}$ person) increased by a factor of 5 and 25, and not by a factor of at least 100, as is usual in toxicological safety testing. Also from a read-across perspective, only half of the CMO2 metabolites formed from $\beta$-cryptoxanthin would be theoretically common to those from zeaxanthin. So ignoring any possible kinetic differences, $37.5 \mu \mathrm{g} / \mathrm{kg}$ bw/day possibly only corresponds to $18.75 \mu \mathrm{g} / \mathrm{kg}$ bw/day in terms of zeaxanthin dosage, or $1.3 \mathrm{mg} /$ day for a $70 \mathrm{~kg}$ adult. The relative "internal" human dose could be even lower if systemic carotenoid absorption in the ferret is lower than in man, as indicated by the authors [54].

So from this study with $\beta$-cryptoxanthin in ferrets, it is considered that zeaxanthin supplementation at low intakes is unlikely to exacerbate the occurrence of lung cancer and might even have a protective effect against the occurrence of squamous metaplasia. However, due to the low dosages of $\beta$ cryptoxanthin used, the extent to which the dosage-related influences might extend to higher intakes of $\beta$-cryptoxanthin or intakes of zeaxanthin above $1.3 \mathrm{mg}$ /day is unclear.

\section{Summary and Discussion}

A series of well-conducted safety studies are available and provide a good basis for a safety assessment of zeaxanthin. Acute studies in rats and mice show a low order of acute toxicity with $\mathrm{LD}_{50}$ values greater than 4000 and $8000 \mathrm{mg} / \mathrm{kg}$, respectively. Subchronic safety studies demonstrated that repeated intakes of high oral doses up to $1000 \mathrm{mg} / \mathrm{kg}$ bw/day in rat and mouse and $400 \mathrm{mg} / \mathrm{kg}$ bw/day in the dog are well tolerated systemically. The macroscopic observation of yellow discoloration of the adipose tissue, which can be attributed to the presence of the zeaxanthin, indicates that there was systemic exposure in these studies and this has been analytically confirmed by analysis of plasma and liver samples in the two-generation rat study. Despite the systemic exposure and high dosages, no target organ toxicity was identified in the subchronic studies during the in-life phase or by pathological/histopathological evaluation.

In developmental toxicity studies, there was no evidence of maternal toxicity, fetal toxicity, or teratogenicity in treated rats or rabbits at doses up to $1000 \mathrm{mg} / \mathrm{kg} /$ day and $400 \mathrm{mg} / \mathrm{kg} /$ day, respectively.

For zeaxanthin, there is no chronic study in rodents, as is also the case for lutein, but there is a two-generation study. This study design involves exposure to test compounds beginning before mating, continuing during mating and 
throughout gestation and lactation, until weaning, and covers all reproductive life phases over two generations. The new version of the study design finalized in 2001 introduced a range of additional end-points focused on detection of fine disturbances of reproductive function and fertility. Such studies can sometimes give a lower NOAEL than respective subchronic toxicity studies, in a similar way that the NOAELs from chronic studies in general are lower than in corresponding subchronic studies. Indeed, on the basis of the dosages for which data was available, the NOAEL from the rat twogeneration study with zeaxanthin $(150 \mathrm{mg} / \mathrm{kg}$ bw/day) was a factor of 6.7 down from the NOAEL in the subchronic rat study.

Potentially, the high systemic exposure observed in young animals during the lactation phase of the two-generation study, from a combination of intake from maternal milk and direct feeding, may have contributed to an effect of treatment occurring at a lower nominal dosage than in the other safety studies. Irrespective of the reason, the lowest dosage from repeat dose toxicity studies was the intermediate dosage of $150 \mathrm{mg}$ zeaxanthin/kg bw/day.

ADME studies in the rat showed that zeaxanthin was rapidly but incompletely absorbed after oral administration following a single dose of ${ }^{14} \mathrm{C}$-zeaxanthin and there is a wide bodily distribution with clear deposition in fatty tissues reflecting the lipophilic nature of zeaxanthin. In addition to specific ADME studies, important information on the potential to bioaccumulate can be obtained from samples taken during the course of the toxicology studies. As referred to in the two-generation study, there is evidence of accumulation in the liver in comparison to concentrations in the plasma.

Metabolite studies have shown there is eccentric $\mathrm{CMO} 2$ cleavage of zeaxanthin and other xanthophylls but for zeaxanthin, being symmetric, only two rather than four metabolites are expected. Both $\mathrm{CMO} 2$ cleavage metabolites of zeaxanthin occur as cleavage metabolites of lutein and $\beta$-cryptoxanthin.

Genotoxicity studies are important studies to indicate if there is interaction with DNA. When unformulated pure crystalline zeaxanthin is exposed to air and light, there may be a potential for mutagenic breakdown products to occur. However, DSM formulated zeaxanthin contains antioxidants that prevent the degradation of zeaxanthin. No mutagenicity was observed in the Ames test with zeaxanthin, or crystalline zeaxanthin retained beyond the shelf life, or in cultures of V79 at the HGPRT locus. No evidence of Unscheduled DNA Synthesis was detected in rat hepatocytes up to the highest dose tested. There was no evidence of clastogenic potential with or without metabolic activation from tests with peripheral blood lymphocytes at doses. In the in vivo mouse micronucleus test, there was no evidence for mutagenicity or clastogenicity. It is concluded that there is no evidence for mutagenicity or clastogenicity with formulated zeaxanthin under appropriate conditions of use.

Based on the wide range of genotoxicity studies with no indication of DNA damage and the absence of any indication of preneoplastic organ changes in repeat dose toxicity studies, and the absence of clear liver enzyme induction effect for lutein, no carcinogenic hazard is expected from direct intake of zeaxanthin.

The question as to whether these xanthophylls might exacerbate the incidence of lung tumors in heavy smokers, as was demonstrated to occur for high dosages of $\beta$-carotene in two human intervention studies [51,52], has only been partly addressed by using published studies in ferrets for this related xanthophyll. The ferret model with exposure to cigarette smoke has been positively validated for $\beta$-carotene [53] and the metabolite overlap has enabled theoretical use of a study with $\beta$-cryptoxanthin to support the safety of zeaxanthin, on a read-across basis. Although the study showed a protective effect of $\beta$-cryptoxanthin against pulmonary squamous metaplasia, the potential applicability of this data for zeaxanthin intake was considered to be limited, due to the low $\beta$-cryptoxanthin dosages that were used in the study.

Besides this study in ferrets, a pooled analysis of seven cohort studies demonstrated that the association between intake of xanthophylls (lutein or lutein plus zeaxanthin) and the risk of lung cancer was negative in smokers and nonsmoking subjects [55].

In general, the structural similarity of the xanthophyll compounds might be considered sufficient to enable the principles of read-across, where there are safety data gaps, as has been done with the $\beta$-cryptoxanthin data in ferrets. However, it appears to be the case that, in the human and primate eye, there is a notable specificity in biological differentiation between the xanthophyll isomers [56]. With this being the case, there is the need for caution in carrying across information from one of these related substances to another, at least in respect to the primate eye.

The animal safety data for lutein and meso-zeaxanthin is notably less than what is available for zeaxanthin. EFSA has reviewed the available data for lutein [36]. For mesozeaxanthin, there is published safety information [57]. In genotoxicity studies reported by $\mathrm{Xu}$ et al., there was no evidence of genotoxicity, which is consistent with the data for zeaxanthin. The NOAEL from their 13-week rat toxicity study was $300 \mathrm{mg} / \mathrm{kg}$ bw/day with clear adverse effects in the liver being reported at the higher dosages of 600 and $1200 \mathrm{mg} / \mathrm{kg}$ bw/day. This is in contrast to the subchronic safety data for synthetic zeaxanthin, where higher NOAELs were obtained with no indication of liver toxicity. No published regulatory 13 -week rat study with $\beta$-cryptoxanthin could be located although there is ADME data in the rat following chronic oral intake [58].

There is a publication reporting toxicology studies for a lutein and zeaxanthin concentrate from marigold flowers (Tagetes erecta $L$.), with a minimum $80 \%$ carotenoid content [59]. In the subchronic study, Wistar rats were administered the concentrate at dose levels of $0,4,40$, and $400 \mathrm{mg} / \mathrm{kg}$ bw/day (gavage) for 13 weeks with no toxicologically significant treatment-related changes. The dosage in terms of zeaxanthin, at the high dose, can be calculated to be $21.6 \mathrm{mg} / \mathrm{kg}$ bw/day (taking $7.5 \%$ of the carotenoid content to be zeaxanthin).

In a recent publication of safety studies of the zeaxanthin concentrate OmniXan, RR-zeaxanthin 65\% enriched product obtained from paprika [60], there was no indication of 
genotoxicity. In the 13-week rat toxicity study, the highest dosage in terms of concentrate was $400 \mathrm{mg} / \mathrm{kg}$ bw/day and this was considered the NOAEL.

A known profile of human response that has been observed in the past in humans, with a high intake of the carotenoid canthaxanthin, is accumulation in the eye and for so-called "canthaxanthin retinopathy." The accumulation in the eyes, however, was not found to be functionally harmful and gradually reversible following discontinuation of consumption. Nevertheless, this accumulation is regarded as undesirable and has been evaluated as an adverse effect by EFSA [61].

A chronic study with synthetic zeaxanthin in Cynomolgus monkeys, an animal model used to investigate the induction and dose dependency of canthaxanthin crystal formation in the retina, has been undertaken involving a comprehensive battery of ocular testing as well as usual toxicological endpoints. Overall, there were no clinical and no morphological evidence for treatment-related adverse changes in the eyes and specifically no evidence for crystal formation in the eyes of treated monkeys.

In the safety evaluation of dietary substances, including nutritional substances being consumed at higher intakes than traditionally occurs, human data needs to be kept in mind as it becomes available. A number of human intervention studies have been undertaken or are in progress with respect to investigating the protective function for zeaxanthin and lutein in the eye. These studies indicate good systemic tolerance of zeaxanthin. At the upper end of the dosage range were a study with a dose of up to $20 \mathrm{mg} /$ day for up to 6 months [62] and a study with $8 \mathrm{mg} /$ day for a year, both without evidence of adverse effects. A further study has been more recently reported in which 24 subjects were supplemented with $20 \mathrm{mg} /$ day of zeaxanthin over 4 months, without any adverse effects $[63,64]$.

4.1. ADI (Acceptable Daily Intake). In the 13-week subchronic toxicity studies, the NOAEL in all cases was the highest dosage investigated, namely, $1000 \mathrm{mg} / \mathrm{kg}$ bw/day in the mouse and rat and at least $422 \mathrm{mg} / \mathrm{kg}$ bw/day in the dog. A traditional approach of a 100-fold safety factor in conjunction with the lowest relevant NOAEL from the safety studies would be used to derive the ADI.

For zeaxanthin, the lowest NOAEL from a standard regulatory study was $150 \mathrm{mg}$ zeaxanthin/kg bw/day in the two-generation study in rats. This NOAEL is at least a factor of 6.7 lower than the NOAEL in the 13-week rat study ( $>1000 \mathrm{mg} / \mathrm{kg}$ bw/day). In their evaluation of the safety of synthetic zeaxanthin as a Novel Food, the EFSA Panel on Dietetic Products, Nutrition, and Allergies (NDA) [37] used the $150 \mathrm{mg} / \mathrm{kg}$ bw/day NOAEL with a 200 -fold safety factor to define an ADI of $0.75 \mathrm{mg} / \mathrm{kg}$ bw/day, or $53 \mathrm{mg} /$ day for a $70 \mathrm{~kg}$ adult (70 kg is the new default human weight used by EFSA). Use of the lowest NOAEL for ADI calculations, as was done by the NDA Scientific Panel, is the traditional precautionary approach used in safety evaluation. The NDA Scientific Panel stated that a daily intake of $53 \mathrm{mg}$ for a person with a body weight of $70 \mathrm{~kg}$ does not raise safety concerns and that the use level of $2 \mathrm{mg} /$ day requested by the applicant was confirmed as safe.

In the case of lutein, the EFSA Panel on Food Additives and Nutrient Sources added to Food (ANS) in their reevaluation [36] introduced an additional safety factor of 2 (making a total 200-fold safety factor), due to the absence of chronic studies or a multigeneration reproductive toxicity study. Additional factors taken into account were that the other data (reproductive studies and genotoxicity data) did not indicate a cause for concern and that lutein is a normal constituent of the diet. The highest dose tested for lutein in a comprehensive 13 -week rat toxicity study was $200 \mathrm{mg} / \mathrm{kg}$ bw/day and this was the NOAEL. The EFSA ANS Panel applied a 200-fold factor to this NOAEL giving an ADI of $1 \mathrm{mg} / \mathrm{kg}$ bw/day or $60 \mathrm{mg}$ lutein/day for an adult.

As a passing comment, application of the 200-fold factor to the rat zeaxanthin subchronic data would give a 5-fold higher ADI than for lutein, due to the higher dosages used and the higher NOAELs that were established for zeaxanthin.

In the United States, synthetic zeaxanthin is marketed since 2002 under the Generally Regarded as Safe legislation, based on DSM safety studies available at the time, with use level in foods and beverages of $0.25 \mathrm{mg} /$ serving.

The use level of zeaxanthin of $2 \mathrm{mg}$ /day proposed by the applicant was ratified by the European Union (EU) Commission in 2013 [65]. However, this upper use level is much lower than the safe level (53 mg/day) defined for zeaxanthin by the NDA Scientific Panel. Potentially, therefore, the currently approved level for synthetic zeaxanthin in Europe could be set as a higher level. Probably, this could be closer to the ADI calculated by the NDA Panel. This ADI ( $53 \mathrm{mg} /$ day) is similar to the ADI of $60 \mathrm{mg}$ /day currently defined by EFSA for lutein [36].

\section{Conclusion}

Zeaxanthin was negative for mutagenic and clastogenic activity in a comprehensive battery of in vitro and in vivo tests for genotoxicity. Based on these studies, it is concluded that there is no evidence for mutagenicity or clastogenicity with formulated zeaxanthin under appropriate conditions of use.

In repeat dose toxicity studies in the rat, mouse, and dog, synthetic zeaxanthin was well tolerated at high dosages with no indication of target organ toxicity or preneoplastic organ changes. Taken together, these data indicate that no carcinogenic hazard is expected from direct intake of zeaxanthin. A study in primate did not indicate any evidence of ocular toxicity or excessive accumulation. A published study in ferret provides limited support for the absence of any stimulating effect of zeaxanthin consumption on the incidence of lung cancer in heavy smokers.

The regulatory study that gave rise to the lowest overall NOAEL of $150 \mathrm{mg}$ zeaxanthin/kg bw/day was a comprehensive two-generation study in the rat. In their evaluation of the safety of synthetic zeaxanthin as a Novel Food, the EFSA NDA Scientific Panel [37] applied a 200-fold safety factor to this NOAEL to define an ADI of $0.75 \mathrm{mg} / \mathrm{kg}$ bw/day, or $53 \mathrm{mg} /$ day for a $70 \mathrm{~kg}$ adult. The EU in 2013 [65] formally approved upper use levels of $2 \mathrm{mg} /$ day (equivalent to 
$0.03 \mathrm{mg} / \mathrm{kg}$ bw/day) as this was the use level proposed by the applicant.

Information from human intervention studies also supports that an intake higher than $2 \mathrm{mg} /$ day is safe, and an intake level of $20 \mathrm{mg} /$ day for up to 6 months was without adverse effect.

\section{Disclosure}

The studies referred to in this publication are principally the work of many dedicated toxicologists and safety specialists over a number of years and are not the work of the author.

\section{Conflict of Interests}

The author is an employee of DSM Nutritional Products Ltd., which manufactures synthetic zeaxanthin.

\section{Acknowledgment}

Dr. Wolfgang Schalch is thanked for his help in editing this paper.

\section{References}

[1] A. Perry, H. Rasmussen, and E. J. Johnson, "Xanthophyll (lutein, zeaxanthin) content in fruits, vegetables and corn and egg products," Journal of Food Composition and Analysis, vol. 22, no. 1, pp. 9-15, 2009.

[2] O. Sommerburg, J. E. E. Keunen, A. C. Bird, and F. J. G. M. van Kuijk, "Fruits and vegetables that are sources for lutein and zeaxanthin: the macular pigment in human eyes," British Journal of Ophthalmology, vol. 82, no. 8, pp. 907-910, 1998.

[3] F. Y. Mohamedshah, J. S. Douglass, M. M. Amann, and J. T. Heimbach, "Dietary intakes of lutein-zeaxanthin and total carotenoids among Americans age 50 and above," The FASEB Journal, vol. 13, no. 4, part 1, abstract 441.17, p. A554, 1999.

[4] J. M. Seddon, U. A. Ajani, R. D. Sperduto et al., "Dietary carotenoids, vitamins $\mathrm{A}, \mathrm{C}$, and $\mathrm{E}$, and advanced age-related macular degeneration," Journal of the American Medical Association, vol. 272, no. 18, pp. 1413-1420, 1994.

[5] G. I. Albert, U. Hoeller, J. Schierle, M. Neuringer, E. J. Johnson, and W. Schalch, "Metabolism of lutein and zeaxanthin in rhesus monkeys: identification of $\left(3 R, 6^{\prime} R\right)$ - and $\left(3 R, 6^{\prime} S\right)-3^{\prime}$-dehydrolutein as common metabolites and comparison to humans," Comparative Biochemistry and Physiology B: Biochemistry and Molecular Biology, vol. 151, no. 1, pp. 70-78, 2008.

[6] E. J. Johnson, M. Neuringer, R. M. Russell, W. Schalch, and D. M. Snodderly, "Nutritional manipulation of primate retinas. III. Effects of lutein or zeaxanthin supplementation on adipose tissue and retina of xanthophyll-free monkeys," Investigative Ophthalmology and Visual Science, vol. 46, no. 2, pp. 692-702, 2005.

[7] W. Schalch, "Carotenoids in the retina-a review of their possible role in preventing or limiting damage caused by light and oxygen," in Free Radicals and Aging, I. Emerit and B. Chance, Eds., vol. 62 of EXS, pp. 280-298, Birkhäuser, Basel, Switzerland, 1992.

[8] W. Schalch, P. Dayhaw-Barker, and F. M. Barker, "The carotenoids of the human retina," in Nutritional and Environmental
Influences on the Eye, A. Taylor, Ed., pp. 215-250, CRC Press, Boca Raton, Fla, USA, 1999.

[9] JECFA, "Safety evaluation of certain food additives," in Proceedings of the 63rd Meeting of the Joint FAO/WHO Expert Committee on Food Additives (JECFA '06), vol. 54 of International Programme on Chemical Safety, World Health Organization, World Health Organization, 2006.

[10] G. B. Arden and F. M. Barker, "Canthaxanthin and the eye: a critical ocular and toxicological assessment," Journal of Toxicology. Cutaneous and Ocular Toxicology, vol. 10, pp. 115-155, 1991.

[11] R. Goralczyk, "Histological aspects of primate ocular toxicity with special emphasis on canthaxanthin-induced retinopathy in an animal model with cynomolgus monkeys," in Towards New Horizons in Primate Toxicology, R. Korte and G. F. Weinbauer, Eds., pp. 159-174, Waxmann Münster, 2002.

[12] R. Goralczyk, F. M. Barker, S. Buser, H. Liechti, and J. Bausch, "Dose dependency of canthaxanthin crystals in monkey retina and spatial distribution of its metabolites," Investigative Ophthalmology and Visual Science, vol. 41, no. 6, pp. 1513-1522, 2000.

[13] R. Goralczyk, S. Buser, J. Bausch, W. Bee, U. Zühlke, and F. M. Barker, "Occurrence of birefringent retinal inclusions in cynomolgus monkeys after high doses of canthaxanthin," Investigative Ophthalmology and Visual Science, vol. 38, no. 3, pp. 741-752, 1997.

[14] E. Gocke, "Mutagenicity evaluation of zeaxanthin, Ro 019509/007 in the Salmonella/microsome assay (Ames test)," DSM Report B-0153207, 1987.

[15] E. Gocke, Decay of (3R, $\left.3^{\prime} R\right)$-Zeaxanthin, Internal Communication, Hoffmann-La Roche, Basel, Switzerland, 1987.

[16] E. Gocke, "Ro 01-9509/007: bacterial reverse mutation test (Ames test)," DSM Report 1015664, 2004.

[17] R. Strobel, "Gene mutation assay in cultured mammalian cells with Ro 01 9509/007 (All-Trans-Zeaxanthin) (V79/HGPRT Test)," DSM Report B-0153078, 1986.

[18] R. Strobel, "Unscheduled DNA synthesis assay with the carotenoid Ro 01-9509/007 (all-trans-Zeaxanthin) using primary cultures of rat hepatocytes," DSM Report B-0153081, 1987.

[19] R. Strobel and A. Bonhoff, "Chromosome analysis of human peripheral blood lymphocytes exposed in vitro to the carotenoid Ro 01-9509/007 (all-trans-(3R, 3'R) zeaxanthin) in the presence and absence of a rat liver activation system," DSM Report B-0153083, 1987.

[20] F. Galandere, "Mutagenicity studies with Ro 01-9509 in mammalian systems, 1 . The micronucleus test in the mouse," DSM Report B-0090156, 1980.

[21] H. P. Baechtold, "Acute toxicity studies with zeaxanthin and its precursors," Interoffice Memorandum 7100, Hoffmann-La Roche, Basel, Switzerland, 1977.

[22] G. Klecak and H. Geleick, "Determination of allergenicity of colorants used in products of the pharmaceutical, cosmetic and nutrition industries in Guinea pigs," DSM Report B-0076538, 1977.

[23] M. Csato and G. Arcelin, "Ro 01-9509/000 (zeaxanthin): study of skin sensitization in albino Guinea pigs: maximization-test," DSM Report B-0171910, 2000.

[24] M. Csato and G. Arcelin, "Primary eye irritation study in rabbits," DSM Report B-0171911, 2000.

[25] R. Ettlin, A. Steiger, and H. Hummler, "Tolerance study with Ro $01-9509 / 007$ (zeaxanthin as $10 \%$ water soluble beadlets) administered orally as a feed admixture to mice over 13 weeks," DSM Report B-0093153, 1980. 
[26] R. Ettlin, A. Steiger, and H. Hummler, “Tolerance study with Ro $01-9509 / 007$ (zeaxanthin as $10 \%$ water soluble beadlets) administered orally as a feed admixture to rats over 13 weeks," DSM Report B-0093152, 1980.

[27] S. Buser, "A 13-week toxicity study with Ro 01-9509/013 in the rat p.o. (feed admix)," DSM Report B-0105657, 1985.

[28] R. A. Ettlin, "13 Week tolerance study of Ro 01-9509/013 administered orally in capsules to dogs," DSM Report B-0105639, 1985.

[29] A. Kistler, "Embryotoxicity and teratogenicity study in rats with oral administration (feed admix) of Ro 01-9509, zeaxanthin. Segment II-teratological study with postnatal evaluation," DSM Report B-0104974, 1984.

[30] A. Kistler, "Embryotoxicity and teratogenicity study in rabbits with oral administration of Ro 01-9509, zeaxanthin. Segment IIteratological study," DSM Report B-0104954, 1983.

[31] J. Edwards, S. Clode, J. Schierle, and N. Decker, "Zeaxanthin 10\% WS beadlets (Ro 01 9509): two generation oral (dietary administration) reproduction toxicity study in the rat," DSM Report No-2500072, 2006.

[32] S. Gradelet, P. Astorg, J. Leclerc, J. Chevalier, M.-F. Vernevaut, and M.-H. Siess, "Effects of canthaxanthin, astaxanthin, lycopene and lutein on liver xenobiotic-metabolizing enzymes in the rat," Xenobiotica, vol. 26, no. 1, pp. 49-63, 1996.

[33] E. Wolz, H. Liechti, B. Notter, G. Oesterhelt, and A. Kistler, "Characterization of metabolites of astaxanthin in primary cultures of rat hepatocytes," Drug Metabolism and Disposition, vol. 27, no. 4, pp. 456-462, 1999.

[34] P. Astorg, S. Gradelet, J. Leclerc, and M.-H. Siess, "Effects of provitamin A or non-provitamin A carotenoids on liver xenobiotic-metabolizing enzymes in mice," Nutrition and Cancer, vol. 27, no. 3, pp. 245-249, 1997.

[35] A. Kistler, H. Liechti, L. Pichard et al., "Metabolism and CYPinducer properties of astaxanthin in man and primary human hepatocytes," Archives of Toxicology, vol. 75, no. 11, pp. 665-675, 2002.

[36] EFSA ANS Panel, "Scientific opinion on the re-evaluation of lutein (E 161b) as a food additive," EFSA Journal, vol. 8, no. 7, article 1678, 2010.

[37] EFSA NDA Panel, "Statement on the safety of synthetic zeaxanthin as an ingredient in food supplements," EFSA Journal, vol. 10, no. 10, article 2891, 2012.

[38] D. Glatzle, J. Bausch, and F. Ringenbach, "Radioactivity in expired air during zeaxanthin balance studies compared to previous findings for canthaxanthin and astaxanthin with rats," DSM Report B-0106789, 1999.

[39] J. Bausch, D. Glatzle, M. Bruchlen, and H. Liechti, "Zeaxanthin distribution study in rats," DSM Report B 0106776, 1999.

[40] D. Glatzle, J. Bausch, S. Moalli, F. Ringenbach, and U. Matter, "Zeaxanthin balance studies," DSM Report B-0106788, 1999.

[41] K.-Q. Hu, C. Liu, H. Ernst, N. I. Krinsky, R. M. Russell, and X.D. Wang, "The biochemical characterization of ferret carotene$9^{\prime}, 10^{\prime}$-monooxygenase catalyzing cleavage of carotenoids in vitro and in vivo," Journal of Biological Chemistry, vol. 281, no. 28, pp. 19327-19338, 2006.

[42] J. R. Mein, G. G. Dolnikowski, H. Ernst, R. M. Russell, and X.-D. Wang, "Enzymatic formation of apo-carotenoids from the xanthophyll carotenoids lutein, zeaxanthin and $\beta$-cryptoxanthin by ferret carotene-9', 10'-monooxygenase," Archives of Biochemistry and Biophysics, vol. 506, no. 1, pp. 109-121, 2011.
[43] D. Hartmann, P. A. Thürmann, V. Spitzer, W. Schalch, B. Manner, and W. Cohn, "Plasma kinetics of zeaxanthin and 3 ' dehydro-lutein after multiple oral doses of synthetic zeaxanthin," The American Journal of Clinical Nutrition, vol. 79, no. 3, pp. 410-417, 2004.

[44] F. Pfannkuch, E. Wolz, C. P. Aebischer, J. Schierle, B. Niggemann, and U. Zuhlke, "Ro 01-9509 (zeaxanthin 10\%) and Ro 153971 (lutein 10\%): combined 52-week oral (gavage) pilot toxicity study with two carotenoids in the cynomolgus monkey," DSM Report and Subsequent Report Addenda B-0171423, 2000.

[45] F. Pfannkuch, "Ro 01-9509 (zeaxanthin 10\%) and Ro 15-3971 (lutein 10\%): combined 52-week oral (gavage) pilot toxicity study with two carotenoids in the cynomolgus monkey (Roche research report No.: B-0171423), comprehensive overview on eye examinations," DSM Report 1004238, 2001.

[46] E. Zrenner, "Additional evaluation of electroretinography (ERG) and expert commentary," Roche Addendum 12, 2000, Regulatory Document 1003501, 2000.

[47] R. Goralczyk, F. Barker, O. Froescheis et al., "Ocular safety of lutein and zeaxanthin in a long-term study in cynomolgous monkeys," Investigative Ophthalmology \& Visual Science, vol. 43, no. 12, p. 2546, 2002, ARVO Meeting Abstracts.

[48] R. Goralczyk, "Ro 01-9509 (zeaxanthin 10\%) and Ro 15-3971 (lutein 10\%): combined 52-week oral (gavage) pilot toxicity study with two carotenoids in the cynomolgus monkey, pathology report on eyes, amendment to final report no. 11," DSM Report 1003526, 2000.

[49] O. Froescheis, B. Rossi, and J. Bausch, "Determination of lutein and zeaxanthin in retina and lens by HPLC," Regulatory Document 1003501, Hoffmann-La Roche, 2000, Addendum No. 12, in Amendment to Final Report No. 1.

[50] F. Khachik, E. London, F. F. De Moura et al., "Chronic ingestion of $\left(3 R, 3^{\prime} R, 6^{\prime} R\right)$-lutein and $\left(3 R, 3^{\prime} R\right)$-zeaxanthin in the female rhesus macaque," Investigative Ophthalmology \& Visual Science, vol. 47, no. 12, pp. 5476-5486, 2006.

[51] ATBC Study Group, "The effect of vitamin E and beta carotene on the incidence of lung cancer and other cancers in male smokers," The New England Journal of Medicine, vol. 330, no. 15, pp. 1029-1035, 1994.

[52] G. S. Omenn, G. E. Goodman, M. D. Thornquist et al., "Chemoprevention of lung cancer: the beta-carotene and Retinol Efficacy Trial (CARET) in high-risk smokers and asbestos-exposed workers," IARC Scientific Publications, vol. 136, pp. 67-85, 1996.

[53] C. Liu, X.-D. Wang, R. T. Bronson, D. E. Smith, N. I. Krinsky, and R. M. Russell, "Effects of physiological versus pharmacological $\beta$-carotene supplementation on cell proliferation and histopathological changes in the lungs of cigarette smokeexposed ferrets," Carcinogenesis, vol. 21, no. 12, pp. 2245-2253, 2000.

[54] C. Liu, R. T. Bronson, R. M. Russell, and X.-D. Wang, “ $\beta$ Cryptoxanthin supplementation prevents cigarette smokeinduced lung inflammation, oxidative damage, and squamous metaplasia in ferrets," Cancer Prevention Research, vol. 4, no. 8, pp. 1255-1266, 2011.

[55] S. Männistö, S. A. Smith-Warner, D. Spiegelman et al., "Dietary carotenoids and risk of lung cancer in a pooled analysis of seven cohort studies," Cancer Epidemiology Biomarkers and Prevention, vol. 13, no. 1, pp. 40-48, 2004.

[56] R. A. Bone, J. T. Landrum, L. M. Friedes et al., "Distribution of lutein and zeaxanthin stereoisomers in the human retina," Experimental Eye Research, vol. 64, no. 2, pp. 211-218, 1997. 
[57] X. Xu, L. Zhang, B. Shao, X. Sun, C.-T. Ho, and S. Li, "Safety evaluation of meso-zeaxanthin," Food Control, vol. 32, no. 2, pp. 678-686, 2013.

[58] M. Sugiura, K. Ogawa, and M. Yano, "Absorption, storage and distribution of $\beta$-cryptoxanthin in rat after chronic administration of satsuma mandarin (Citrus unshiu MARC.) juice," Biological and Pharmaceutical Bulletin, vol. 36, no. 1, pp. 147151, 2013.

[59] R. Ravikrishnan, S. Rusia, G. Ilamurugan et al., "Safety assessment of lutein and zeaxanthin (Lutemax 2020): subchronic toxicity and mutagenicity studies," Food and Chemical Toxicology, vol. 49, no. 11, pp. 2841-2848, 2011.

[60] K. B. Ravi, K. R. R. Reddy, J. Shankaranarayanan, J. V. Deshpande, V. Juturu, and M. G. Soni, "Safety evaluation of zeaxanthin concentrate (OmniXan): acute, subchronic toxicity and mutagenicity studies," Food and Chemical Toxicology, vol. 72, pp. 3039, 2014.

[61] EFSA ANS Panel, "Scientific opinion on the re-evaluation of canthaxanthin (E $161 \mathrm{~g}$ ) as a food additive," EFSA Journal, vol. 8, no. 10, article 1852, 2010.

[62] J. van de Kraats, M. J. Kanis, S. W. Genders, and D. van Norren, "Lutein and zeaxanthin measured separately in the living human retina with fundus reflectometry," Investigative Ophthalmology and Visual Science, vol. 49, no. 12, pp. 5568-5573, 2008.

[63] G. Forma, G. Carboni, B. J. Jennings, and A. Iannaccone, "Measures of macular function after dietary supplementation with zeaxanthin (Zx)," Investigative Ophthalmology \& Visual Science, vol. 52, no. 6, p. 3637, 2011, ARVO Meeting Abstracts.

[64] G. Carboni, G. Forma, B. J. Jennings, and A. Lannaccone, "Effects of zeaxanthin $(\mathrm{Zx})$ supplementation on macular pigment optical density (MPOD)," Investigative Ophthalmology \& Visual Science, vol. 52, abstract 3622, 2011, ARVO Meeting Abstracts.

[65] EU Commission, "Commission implementing decision of 22 January 2013, authorising the placing on the market of synthetic zeaxanthin as a novel food ingredient under regulation (EC) No 258/97 of the European Parliament and of the Council," Official Journal of the European Union, 24.1.2013, 2013. 


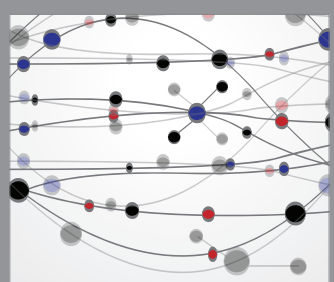

The Scientific World Journal
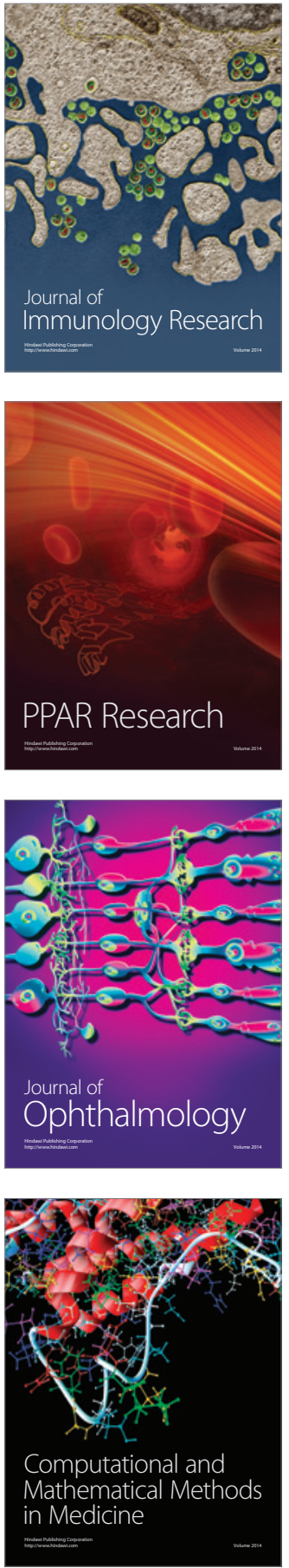

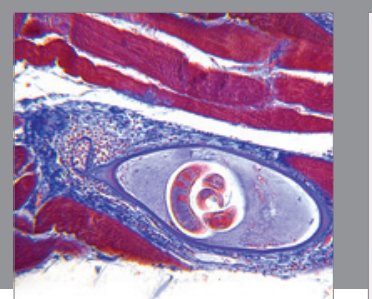

Gastroenterology Research and Practice

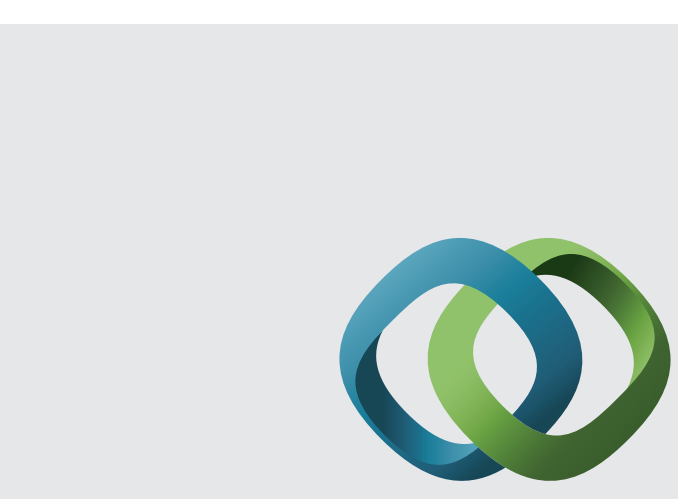

\section{Hindawi}

Submit your manuscripts at

http://www.hindawi.com
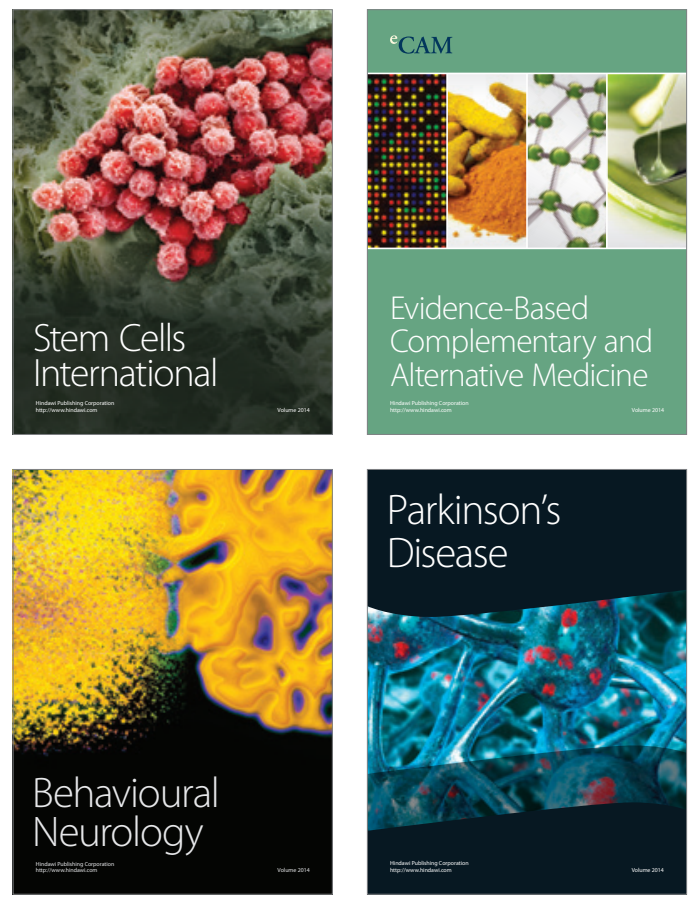
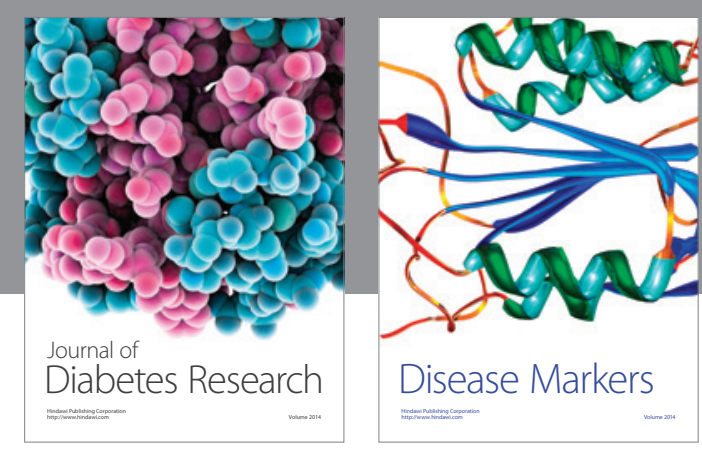

Disease Markers
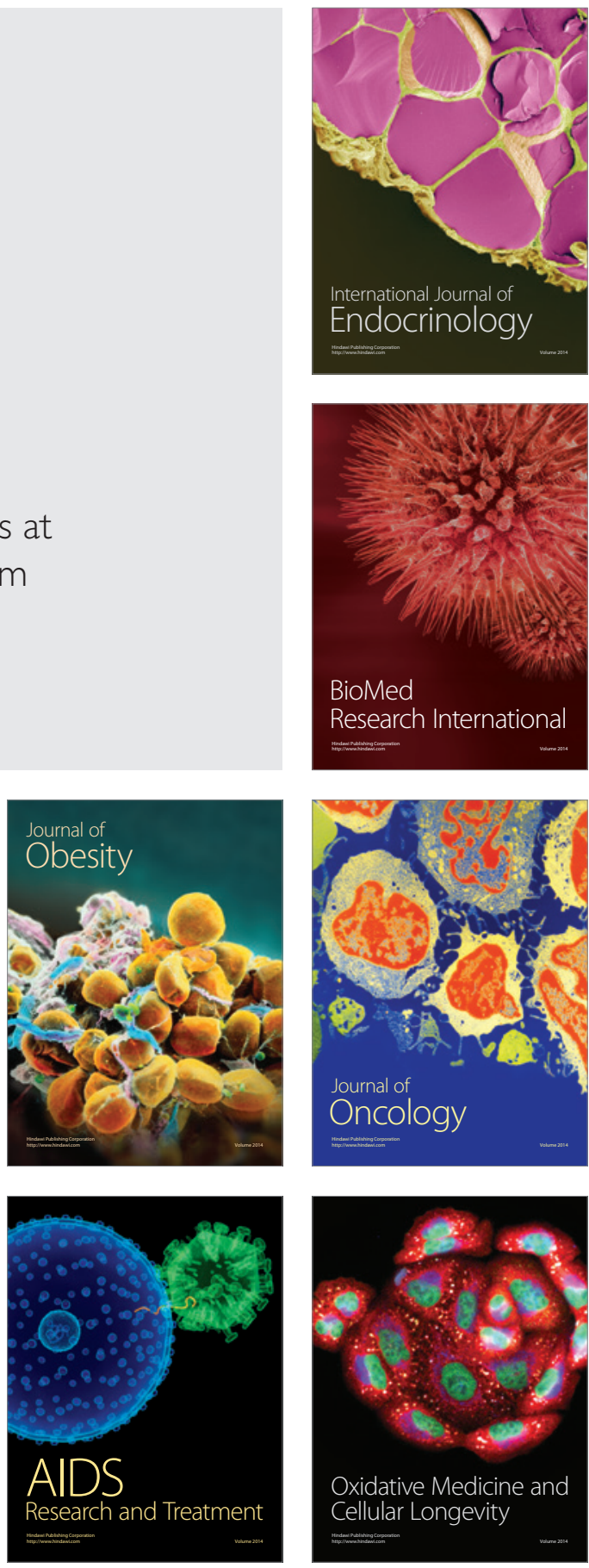